PAISAGENS ARRUINADAS (E A DELICADA ARTE DE COLETAR COGUMELOS)

BLASTED LANDSCAPES (AND THE GENTLE ARTS OF PICKING MUSHROOMS)

Anna Lowenhaupt Tsing

Como citar este artigo:

TSING, Anna Lowenhaupt. Paisagens arruinadas (e a delicada arte de coletar cogumelos). Traduzido por Filipi Pompeu e Mariana Canazaro Coutinho. In: Cadernos do Lepaarq, v. XV, n.30., p. 366-382, Jul-Dez. 2018. 


\title{
Paisagens arruinadas (e a delicada arte de coletar cogumelos) ${ }^{12}$
}

\author{
Anna Lowenhaupt Tsing \\ Traduzido por Filipi Pompeu ${ }^{3}$ e Mariana Canazaro Coutinho ${ }^{4}$
}

Ruínas agora são os nossos jardins. Nossa subsistência é provida por paisagens degradadas, "arruinadas". E mesmo o oásis mais promissor de fartura natural necessita de intervenções massivas para sua manutenção.

Em um movimentado mercado de cogumelos no sudoeste da China, negociantes estavam ansiosos para me explicar porque os japoneses valorizam tanto o matsutake (Tricholoma matsutake), cogumelos silvestres aromáticos, coletados em todo o Hemisfério Norte para exportar para o Japão. Depois do bombardeio atômico de Hiroshima durante a segunda Guerra Mundial, eles contaram, o primeiro ser vivo a crescer na paisagem explodida e arruinadas foi o matsutake. "Esses cogumelos devem ser fortes", imaginaram, afirmando que o consumo dos cogumelos também fortalecia os japoneses. "Matsutake te dá energia", eles dizem.

"Energia" não é como os japoneses descrevem o cogumelo. Mas certamente os chineses da região sudoeste precisam de energia para sobreviver e prosperar em sua própria paisagem rural arruinada, impactada pelas campanhas nacionais de produtividade, saqueada pelas elites corruptas e, acima de tudo, explorada intensamente pela subsistência dos camponeses. Por conta da reputação fortificante do matsutake, sua demanda tem se desenvolvido em toda a China - apesar de não ser parte da culinária tradicional. Talvez a história da multiplicação dos cogumelos, apesar do ataque nuclear, seja uma boa metáfora não apenas para a nova economia capitalista emergindo dos entulhos da modernização socialista, mas também para o papel estimulante dos produtos da floresta, a despeito de um histórico de impactos ambientais.

Há ainda mais ambivalência nesta história. Matsutake, como muitos outros cogumelos, são eficazes coletores de radioatividade. Estes matsutake surgidos das cinzas de Hiroshima podem ter sido fortes, mas também podem ter sido tóxicos para humanos e animais - ao menos a longo prazo. Este conteúdo tóxico, o veneno na oferenda, apenas fortalece a leitura metafórica. Formas emergentes do capitalismo global, dentro dos quais a China é um polo concentrado de atividade, extraem fortunas de paisagens arrasadas como dádiva e veneno. Cadeias de comércio global extraem não apenas commodities, mas também as histórias de violência que tornam possível a produção ultra barata desses bens. Assim como a história da bomba atômica estava incorporada no micélio dos matsutake de Hiroshima, assim, também, cada cadeia de produção de commodities carrega consigo histórias de danos à vida humana e não humana. Cada cogumelo mastutake conta uma história de paisagens arrasadas.

\footnotetext{
O Grupo Mundial de Pesquisa de Matsutake (Timothy Choi, Lieba Faire, Michael Hathaway, Miyako Inoue, Shiho Satsuka e eu) está conduzindo um trabalho colaborativo sobre a cadeia global de commodity do matsutake. Pesquisas na China e no Japão foram promovidas com um subsídio da Toyota Foundation. Sou particularmente grata a Shiho Satsuka e Michael Hathaway por me ensinarem a respeito das paisagens japonesas e chinesas, respectivamente. Muito do material neste capítulo foi obtido através de entrevistas pessoais. Seguindo as convenções da Antropologia Cultural, os entrevistados não foram citados, salvo quando pareceu absolutamente necessário. Entretanto, expresso gratidão especial para Phil Cruz, Anne Harju, Chris Mickle, Ogawa Mankoto, Eira-Maija Savonen, Su Kaimai, Takeuchi Kazuhiko, e Xu Jianchu pela informação coletada neste capítulo. Peço desculpas por quaisquer erros que possa ter introduzido em suas explicações. Também agradeço a Noboru Ishikawa, Eben Kirksey e Heather Swanson por sua ajuda e encorajamento.

${ }^{2}$ Originalmente publicado como "TSING, Anna. Blasted landscapes (and the gentle arts of picking mushrooms). IN: KIRKSEY, Eben (Org.). The Multispecies Salon. Durham: Duke University. 2014. p. 87-109. Autorização da autora cedida em 15/11/2017.

${ }^{3}$ Mestre em História pela Pontifícia Universidade Católica do Rio Grande do Sul (PUCRS), Brasil; Especialista em Arqueologia pela Universidade de Passo Fundo (UPF), Brasil.

${ }^{4}$ Bachelor of Arts in English and History pela Carlow College St. Patricks, Ireland; Graduanda em História pela Pontifícia Universidade Católica do Rio Grande do Sul (PUCRS), Brasil.
} 
Não obstante, a colheita de cogumelos é uma arte delicada e pode nos ensinar lições sobre maneiras de viver juntos em meios impactados. Matsutake nos lembra que algumas, mas não todas, formas de perturbação podem abrigar vida. Ainda não se pode cultivar o matsutake. Ele precisa de ambientes deteriorados por conta de suas relações essenciais com plantas pioneiras e solos mineralizados. Colônias de matsutake, desta forma, ensinam-nos sobre a transformação de mundos e o compartilhamento de energia, indo além dos conceitos de agricultura, com seu apelo a uma harmonia estável entre as pessoas e a cultura $^{5}$. Nesta leitura, é impossível deixar de lado as paisagens arruinadas.

Este capítulo descreve a história ambiental de quatro florestas de matsutake, considerando que diferentes trajetórias de destruição e perturbação são tornadas ecologicamente viáveis, ao menos para algumas relações fitossociais, como entre o matsutake, pinheiros (Pinus sp.) e humanos. Deixe-me ser clara: este exemplo não procura justificar a destruição do meio ambiente, mesmo se aprendemos a conviver com isso. Algumas formas de destruição são piores do que outras para a possibilidade da vida. As florestas de matsutake são paisagens arruinadas vívidas; mas nem toda paisagem arruinada abriga o mesmo tipo de vitalidade.

\section{PAISAGENS DESTRUÍDAS}

No final do século XX, a modernização extraiu grandes montantes da vida no planeta. Florestas tropicais haviam sido derrubadas e saqueadas, depauperando estes antigos ecossistemas permanentemente. Grandes represas silenciam os rios. Salinização e envenenamento químico ameaçam vastas áreas de terra arável. Espécies estavam desaparecendo em ritmo alarmante. Declínio e bancarrota assombravam florestas industriais, outrora vitrines de produtividade sustentável. A emergência de minas, descarte de produção industrial, ruínas de guerra e emissões radioativas, planejadas ou não, varreram com vento e água, cobrindo regiões inteiras.

Talvez não seja por acaso que a consciência popular sobre toda esta destruição surgiu em concomitância com o abandono dos sonhos de empoderamento humano através da melhoria do bem-estar comunal. Governos nacionais têm cada vez mais desistido desta ideia, encorajando, ao invés disso, uma economia desregulada, "cada um por si”, onde todos estão livres para ficar ricos (ou saudáveis, ou bem alimentados) da forma que puderem. Corporações se distanciaram dos padrões de responsabilidade com funcionários ou comunidades para melhor estabelecer seu foco nos lucros da bolsa de valores. É claro, existem exceções, e estas "tendências" são, em grande parte, uma consequência do poder contingente histórico dos Estados Unidos para estabelecer padrões globais. Ainda assim, apesar destas exceções, estas tendências se firmaram no imaginário das pessoas, no mundo todo. Sua influência é mais evidente na expansão de uma "economia oportunista" ${ }^{6}$, tanto entre os pobres quanto entre os empresários poderosos ao redor do globo. Esses oportunistas aproveitam qualquer oportunidade para obter dinheiro $^{7}$. Embora a mendicância sempre tenha sido uma prática popular em países pobres, sua atual apropriação se tornou modelo para a sobrevivência em países ricos também. Trabalhando nas brechas dentro do sistema de regulação, eles procuram as melhores chances para usar suas perícias escusas. Um setor exemplar deste tipo de economia é o tráfico de produtos ilegais (drogas, armas) do século XX; já que as linhas entre legal e ilegal são difíceis de definir para a estratégia oportunista. Mas a fórmula se expandiu além das expectativas do século XX (NORDSTROM, 2007). Cada cidade industrial arrasada, cada cen-

\footnotetext{
$5 \quad$ No sentido agrícola. (nota dos tradutores).

6 O termo original é "scrounging economy", que é de difícil tradução. Em virtude do sentido construído ao redor do oportunismo exercido como tática econômica, sugere-se o conceito em questão.

$7 \quad$ Ainda que por razões diferentes (nota dos tradutores).
} 
tro de agronegócio moderno depopulado, ou monocultura florestal a serviço da indústria; todos estão cheios de oportunistas. Muitos destes um dia foram empregados industriais, fazendeiros ou lenhadores. Hoje, tentam sobreviver entre suas ruínas.

Por sorte, ruínas às vezes estão cheias de tesouros. Em zonas sem radioatividade, cogumelos silvestres são os tesouros menos perigosos e mais vitais que podem ser encontrados. A coleta de cogumelos silvestres é um método de subsistência exemplar entre pessoas desempoderadas, marginais. No colapso econômico depois da queda da União Soviética, muitos russos se voltaram para os cogumelos silvestres, tanto para sua subsistência, como para seu sustento (YAMIN-PASTERNAK, 2007). Enquanto isso, o nicho de mercado gourmet floresceu na indústria alimentícia. Facilitado pela disponibilidade de transporte transcontinental de alta velocidade, o que torna possível exportar cogumelos frescos ao redor do mundo, o valor comercial dos espécimes silvestres decolou. Mas a extremidade coletora deste novo mercado não se rendeu tão facilmente às organizações corporativas. Na maioria das áreas comerciais de coleta, catadores independentes procuram os cogumelos, vendendo-os em pontos de compra. No tecido danificado da gestão moderna de recursos, transformar cogumelos em dinheiro reúne histórias humanas e não-humanas de perturbação radical. Com os cogumelos, pessoas desempoderadas e marginalizadas encontram vida em paisagens arruinadas.

Ruínas viraram nossos jardins.

\section{A VIDA SEM CULTIVO}

Não é favorável glorificar os jardins, que são sempre locais de perturbação, que beneficiam algumas coisas vivas e sentenciam outras à morte. Apenas em ideologias agrárias os jardins significam, simplesmente, o dom da vida. Os costumes “incultivados" dos cogumelos silvestres são bons para pensar na academia porque eles nos guiam para além das expressões idiomáticas da reprodução controlada e benéfica, internalizada em nós pelos regimes de cultivo agrícola. Onde uma orientação agrícola nos encoraja a imaginar uma relação unilateral entre humanos e nossos legumes comestíveis, cogumelos silvestres insistem em ecologias complexas, onde o controle é impossível. E onde uma orientação agrícola nos incita a considerar um regime repetitivo de gerações auto-replicantes, pensar com cogumelos nos introduz para uma história da paisagem sem um final definido. Matsutake são particularmente bons para esta ideia: pesquisadores japoneses têm trabalhado vigorosamente para cultivar o matsutake, mas ainda não foram bem sucedidos.

Não é suficiente afirmar que os matsutake necessitam de uma comunidade ecológica ${ }^{8}$; matsutake são uma comunidade ecológica. Matsutake obtêm seus nutrientes das árvores. Junto às raízes das árvores, articulam estruturas chamadas micorriza. Para cultivar o matsutake, condições ideais não apenas para o fungo, mas para a combinação micorrízica entre fungo e raiz, devem ser criadas (OGAWA, 1978). Relações simbióticas nunca são plácidas. O matsutake estimula o crescimento deformado em "dedos de bruxa" das raízes hospedeiras, e quando o fungo hóspede atinge certa maturidade, eles matam aquela parte do anfitrião. Como um pesquisador da espécie afirmou: "as árvores devem sentir uma coceira (OGAWA, 2008)"”. Não obstante, o fungo traz benefícios evidentes para as raízes, em especial junto a solos empobrecidos de nutrientes, onde a combinação é mais bem sucedida. O matsutake secreta fortes ácidos que dissolvem minerais de rochas e areia, disponibilizando nutrientes para as árvores outrora desprovidas. Este comportamento vicejante é também uma defesa hostil. Matsutake forma densos tapetes miceliais para concentrar seus ácidos digestivos, que repelem a água; esses tapetes também isolam outros fun-

8 Nesta discussão, eu reúno as espécies - bastante aparentadas entre si - que são aceitas no mercado de matsutake japonês, incluindo Tricholoma matsutake, Tricholoma magnivelera e Tricholoma caligatum.

9

Entrevista com a autora.

TSING, Anna Lowenhaupt. Paisagens arruinadas (e a delicada arte de coletar cogumelos). Traduzido por Filipi Pompeu e Mariana Canazaro 
gos e bactérias que também poderiam tornar nutrientes disponíveis (LEFEVRE, 2003) ${ }^{10}$. O termo japonês para esses tapetes, shiro, que significa "castelo", sublinha sua habilidade para a defesa contra outros fungos e bactérias. Se os competidores são muitos, como em melhores solos, o matsutake morre. Assim, a associação entre solos pobres e o matsutake é reforçada. Cultivadores em potencial se frustrariam se insistissem no enriquecimento do solo mais comumente associado à agricultura.

Apenas certas trajetórias históricas permitem a reprodução de uma comunidade ecológica de matsutake. Deve haver solo mineral exposto, às vezes resultante de um grande cataclismo, humano ou não. Deve haver flora pioneira - especialmente pinheiros - que consigam crescer em tais ambientes empobrecidos. $\mathrm{E}$ as florestas devem ter pelo menos quarenta anos de idade. Embora o matsutake possa infectar brotos, o florescimento anual de cogumelos começa entre trinta a quarenta anos. Mas há alguma contradição aqui. No andar natural do tempo, árvores depositam folhas, morrem, e são recicladas por fungos e bactérias. Húmus se acumula, acrescentando nutrição ao solo. Enquanto o solo se desenvolve, uma maior quantidade de plantas e fungos substitui as espécies pioneiras, que podem desaparecer por completo. Quarenta anos é tempo suficiente para que o húmus se desenvolva e que as espécies pioneiras percam sua dominância. Para que uma floresta de matsutake se desenvolva, algum tipo de perturbação deve ser mantido. O ciclo de matéria orgânica e sucessão das espécies deve ser interrompido. Cogumelos matsutake são criaturas dependentes de constante perturbação - das grandes mudanças iniciais, que exterminaram antigas camadas orgânicas, às diárias transformações, que empobrecem tanto o solo quanto a multiplicidade das espécies. E, além disso, eles também são florestas, o que significa que eles devem, de alguma forma, ter sido protegidos da destruição florestal.

Ecologistas das últimas décadas têm chamado a atenção para o fato de que toda história natural é uma história de perturbação. Não é mais possível estabelecer uma dicotomia clara e simples entre paisagens naturais e modificadas. Mas poucos são insensíveis o suficiente para imaginar que, como resultado, não haja diferença entre uma floresta saudável e uma área de descartes de energia nuclear. Ou seja: novos desafios surgem com novas perturbações. Com quais tipos de regimes de impactos ambientais estamos dispostos a conviver? Dadas as realidades dos impactos que nos incomodam, como viveremos? O primeiro passo para responder essas questões é explorar as consequências de certas histórias de perturbação do meio ambiente; talvez, até mesmo, tentar algumas tipologias. Locais onde histórias humanas e não-humanas de perturbação surgem em conjunto são particularmente boas para se pensar, pois tais locais nos permitem rastrear humanos como autores e vítimas destes impactos. Esse é um território de consequências não intencionais, tanto para humanos quanto para não-humanos. Cientistas das ciências naturais e sociais são necessários para essa pesquisa profundamente histórica e precisamente situada.

A cadeia de commodities à qual o matsutake pertence nos ajuda a identificar um tipo particular de floresta perturbada através de seus cogumelos. Descrever tais contextos silvestres pode ajudar a criar um vocabulário voltado para o habitável destas perturbações - o primeiro passo para entrarmos em termos com o ambiente antropogênico que nossa espécie criou. Além do mais, à parte de raríssimas exceções, as florestas não costumam ser planejadas para o matsutake. Diretivas racionais não explicam a ecologia dos matsutake e os impactos ambientais antrópicos não podem ser explicados funcionalmente pela presença do matsutake. Matsutake é uma consequência imprevista, é um produto de algo que alguém poderia chamar, apoiando-se no oxímoro, "design não-intencional" na conjunção da modificação paisagística humana e não-humana. A coleta de cogumelos para a subsistência também é um resultado imprevisto de outras subsistências que deram errado.

Mas nem todas as florestas e coletores de matsutake são iguais; ambas perturbações, humanas e não humanas, são geradas de muitas formas. Para apreciar esses eventos, é necessário uma imersão na história desses locais. Vamos apresentar quatro florestas de matsutake e suas histórias de perturbação.

10 Também; entrevista com a autora em 2007. 


\section{PAISAGEM UM: VASCULHANDO AÇO VERDE}

Michael Hathaway, meu colaborador na China, levou-me a uma série de surpresas durante nossa viagem de pesquisa para Yunnan, em 2009. Embora a maioria dos relatos midiáticos, e mesmo acadêmicos, sobre o neoliberalismo na China foquem nas áreas urbanas, o empreendedorismo desenfreado estava, no mínimo, tão descontrolado e próspero quanto nas remotas áreas montanhosas. Todos queriam iniciar algum negócio, mesmo que parco, da terra. A coleta de cogumelos silvestres é um dos mais exíguos; não exige capital inicial, apenas olhos e pernas saudáveis para começar a trabalhar. Se mulheres e crianças saem toda manhã para esquadrinhar os bosques, é porque a colheita de cogumelos é especialmente atraente para quem não dispõe de outros recursos. Quando ouvi pela primeira vez os dados oficiais sobre 600.000 pessoas no mercado de cogumelos silvestres de Yunnan, achei apenas que não podia ser. Mas depois de observar a cena rural, percebi que poderia ser pouco.

Um número extraordinário de espécies entraram para a comercialização e, durante a temporada, mercados locais e beiras de estrada fervilham de vendedores com cestas cheias de cogumelos coloridos. Aqui a metáfora do veneno na oferenda é excepcionalmente concreta. Alguns coletores que conheci apanhavam todos os cogumelos que encontravam. Os cogumelos mais caros - incluindo matsutake - eram separados para serem vendidos frescos. O resto era fatiado e posto para secar em telas ao sol ou no fogo da cozinha. Nos mercados rurais, cogumelos secos são muitas vezes vendidos em pacotes sortidos, indistintos. Os coletores me contaram que os cogumelos venenosos perdiam suas propriedades nocivas durante a secagem; assim, eles não se preocupavam em diferenciar os comestíveis dos venenosos durante a coleta. Um micologista chinês, descrevendo sua conversa com uma mulher que vendia cogumelos, ofereceu uma outra forma de apresentar esta prática perigosa. "Estes cogumelos são venenosos", ele disse após observar sua cesta. "Sim, eu sei”, ela respondeu. "Eu não os venderia para você. Mas se eu os vender para uma companhia, onde serão misturados com outros cogumelos, isso não importa". A economia de cogumelos silvestres funciona à base de energia oportunística. Sobreviver é vender, não comprar.

Lá as florestas são bastante jovens - e bastante depauperadas pelo uso. No condado rural onde estivemos, vi poucas árvores com mais de quarenta ou cinquenta anos, e colegas chineses disseram que a situação era similar em outros lugares. Nessas florestas de montanha, carvalhos sempre-verdes ofereciam uma recompensa de biodiversidade, mas eram podados para se parecerem com arbustos ${ }^{11}$. Mesmo pinheiros pequenos encontram o sol se elevando sobre eles. Em todo o lugar há sinais de exploração intensiva. Os carvalhos são feitos em toras de lenha, formando grandes pilhas ao lado das casas. Os pinheiros são cortados para material de construção. As folhas em forma de agulha dos pinheiros são usadas como leito para os porcos; a mistura das agulhas de pinheiro e fezes suínas é espalhada nos campos como fertilizante. Cabras e vacas perambulam e pastam em áreas classificadas pelo vago e amplo conceito de "terra estéril". Trilhas se cruzam pela floresta, e seu chão varrido e vasculhado pela procura de cogumelos e ervas diversas é, muitas vezes, nu. Esta é uma versão da floresta satoyama idealizada pelos conservacionistas japoneses, mas parece muito mais caótica que os parques organizados, reconstruídos pelos cidadãos nipônicos.

Descobrir a história destas florestas se provou um tanto difícil. Os pesquisadores chineses, preocupados em se atualizar junto aos colegas internacionais, não desenvolveram o gosto pelos prazeres simples da história oral. Oficiais florestais nos guiaram através de décadas de políticas nacionais, que deixaram as florestas divididas em camadas administrativas sobrepostas, cada uma de mandatos diferentes e, às vezes, contraditórios. Não era à toa que os camponeses contavam histórias idiossincráticas e não raro confusas, nas quais as linhas entre as opções de acesso público e privado, assim como entre a colheita

11 Eu uso o termo "carvalho" com uma amplitude generosa para incluir árvores similares aos carvalhos da família dos abetos, incluindo Lithocarpus e Castanopsis, assim como Quercus. 
legal e ilegal, eram difíceis de traçar. Coletar e organizar tais histórias teria sido um trabalho de amor. Eu fiz esforços heróicos para orientar nosso graduando de Kunming nessa direção, visto que ele procurava um tema de pesquisa. Parece significativo que ele não considerava essa tarefa como "pesquisa".

Ainda assim, parece que muitas destas árvores foram cortadas durante as orientações nacionais de produção do Grande Salto Para Frente, no final de 1950, e talvez nos anos famintos subsequentes. Um camponês que viveu à época nos disse que as florestas eram consideradas "aço verde". Produção em pequena escala - "fundo de quintal" - de aço era um dos objetivos do Grande Salto, e florestas foram derrubadas para servirem como combustível. Quando pressionamos por uma explicação mais concisa, o homem recuou para a conservação moderna de florestas. A dificuldade em corrigir as coisas foi afirmada quando um vizinho se juntou à conversa para descrever o quão fácil era conseguir permissões para cortar árvores no capão de uma das florestas antigas remanescentes nas proximidades. Legalmente, a madeira deveria ser cortada apenas para se construir uma casa, mas a maioria ia para a capital provincial, disse ele. Nosso anfitrião, mais tarde, disse que o vizinho era um fanfarrão mentiroso, porém teve dificuldade em explicar a considerável quantidade de madeira alojada nos fundos de sua própria casa. Fica claro que há muitas histórias interligadas - todas levando a uma jovem e bastante utilizada floresta.

O discurso de sustentabilidade se tornou uma ferramenta de exportação do cogumelo. O sudoeste chinês produz a vasta maioria de cogumelos matsutake consumidos no Japão, muitas vezes enviando mais de mil toneladas anualmente. Além disso, há montanhas de matsutake colhidos, mas rejeitados pelos exportadores, que precisam encontrar compradores domésticos ou serem desperdiçados. Então, não é surpreendente *as preocupações que emergem entre conservacionistas sobre o recurso estar sendo super-explorado. Pesquisadores, oficiais do governo e ONG's se envolveram nesta questão. Têm-se promovido a educação dos coletores, assim como mudanças no acesso ao recurso. Mas, para minha surpresa, dentre as numerosas formas de orientação que têm surgido, apenas uma ganhou força em múltiplos ponto de coleta: "Não peguem os bebês" - isto é, os pequenos, jovens cogumelos.

Não há motivo para se pensar, embasado no conservacionismo, em não juntar os pequenos cogumelos. Coletar em qualquer tamanho priva a população fúngica de novos esporos, mas não fere o corpo micelial que está enterrado no subsolo. O único problema com os cogumelos pequenos é que os importadores japoneses não os compram. Esperar para coletá-los até que fiquem grandes, então, traz mais dinheiro. Mas mais dinheiro para quem? Para empresários que têm acesso aos cogumelos.

Estudos sustentáveis estão promovendo uma particular forma de manejo que salva os bebês: aldeias inteiras subcontratam os direitos aos cogumelos em suas florestas a empreendedores privados, que em troca oferecem pagamento em dinheiro aos aldeões. Então, os empreendedores contratam guardas florestais para manter os aldeões fora de suas florestas. Com a colheita do cogumelo controlada, o matsutake pode ser colhido em um tamanho perfeito, ideal para exportação. Enquanto isso, os acordos oferecem futuras oportunidades empresariais. Em uma floresta vigiada que visitamos, os guardas me venderam o direito de colher o matsutake a um preço inflacionado. Em outra, o empresário nos mostrou como ele procurava por raras árvores florescentes, escavando-as por inteiro para a venda em projetos urbanos de "arborização". Não tenho certeza se a conservação estava sendo respeitada. Os guardas admitiram que raramente mantinham todos os "ladrões" a distância isto é, os aldeões que se esgueiravam para coletar cogumelos em lugares conhecidos há gerações. A ralé competitiva que esse sistema de manejo estava destinada a esmagar, continua voltando, mas com um pouco mais de dificuldade.

Ambos, florestas e pessoas em Yunnan, já passaram por épocas inesperadas. O matsutake florescer lá é, quase certamente, uma característica de um abuso ambiental - as jovens árvores, a poda dos carvalhos, o rastelamento das agulhas de pinheiros. O sucesso dos exportadores em escoar o matsutake é uma característica do espírito empreendedor desesperado que se apoderou dos camponeses recém libertos dos sonhos e garantias comunais. Intrigas e sobrevivência se tornaram difíceis de 
distinguir. Este é um regime de perturbação, no qual ambos, camponeses e cogumelos, aprenderam a encontrar seu caminho. Mas antes que você conclua que estou contando uma história sobre o atraso chinês, deixe-me apontar para uma situação paralela na costa noroeste estadounidense.

\section{PAISAGEM DOIS: NAS RUÍNAS DA INDÚSTRIA FLORESTAL}

Quando os primeiros colonos brancos chegaram ao Oregon, no século XIX, encontraram florestas de proporções míticas. As regiões da Cascádia oriental e central, pinheiros ponderosa (Pinus ponderosa) estavam espaçados entre si como se compusessem parques. Apesar de, em retrospecto, parecer que esses parques foram, em parte, criados pelos nativos estadounidenses para a administração de incêndios, para os colonos, a floresta parecia a terra maravilhosa da madeira. Eles começaram a derrubá-la imediatamente. Não satisfeitos em ver as toras serem retiradas pela força dos bois, o governo cedeu direitos para companhias ferroviárias privadas, que não apenas cortavam as árvores, mas também construíam trilhos de trem para as transportar. Nos começos do século XX, a terra estava ocupada por cidades-serrarias, cheias de lenhadores. Em 1938, o Oregon se tornou o Estado líder, nos EUA, na produção de madeira (COGSWELL, 1981, p. 235-259; LANGSTON, 1995; ROBBINS, 1997, 2004; STEEN, 2004) $)^{12}$.

A pura magnitude da contribuição do Oregon em madeira durante este período tornou o estado uma arena para os embates entre o nascente Serviço Florestal dos EUA e a indústria extrativista. O Serviço Florestal iniciou a virada do século XX preocupado porque a ganância dos lenhadores iria rapidamente destruir toda a floresta. Mas a regulação do governo estadounidense sempre emergiu de um diálogo íntimo com o livre empreendimento; e as normas impostas sobre a madeira não foram diferentes. O Serviço Florestal procurou trabalhar em conjunto com a indústria, desenvolvendo padrões para extração sustentável das florestas, mesmo daquelas que o governo considerava parques nacionais. Se os agentes florestais supervisionaram a indústria ou foram seus representantes, continua sendo uma discussão inacabada. Entretanto, ainda hoje, depois do declínio da atividade madeireira, cada distrito do Serviço Florestal é avaliado pelas tábuas que produzem.

Até o final da Segunda Guerra Mundial, a maior parte da madeira do Oregon foi derrubada em terras privadas. No entanto, durante o boom econômico do pós-guerra, as florestas nacionais foram abertas para operações extrativistas massivas. Os famosos pinheiros ponderosa, das Cáscades orientais, estavam em escassez por volta de 1960. Então, o Serviço Florestal teve que voltar sua atenção para a regeneração deste recurso supostamente renovável. Dado que pinheiros são espécies pioneiras dependentes de luz, parecia lógico abrir a floresta o máximo o possível para favorecer o crescimento das árvores. A prática, chamada "clear-cutting"," , na qual toda a vegetação da floresta era removida, foi implementada para privilegiar os pinheiros. Infelizmente, ao menos nas Cáscades orientais, hoje protegidas dos incêndios, privilegiou-se os pinheiros errados. Ao invés dos valiosos e massivos ponderosas, um pinheiro muito mais estreito e prolífico cresceu nas clareiras: o pinheiro-torcido (Pinus contorta). O pinheiro-torcido nesta área é uma árvore esguia, útil mais para ripas - ou mesmo bio-combustível - do

12 Para minha discussão da história madeireira do Oregon e a paisagem das Cáscades ocidentais eu me apoiei em entrevistas, histórias orais e referências básicas como:

COGSWELL, P. Jr. Deschutes Pine Logging. EM: VAUGN, T. (Ed.). High and Mighty: selected sketches about the Deschutes Country. Portland, Oregon: Oregon Historical Society. Pp. 235-259. 1981.

LANGSTON, N. Forest Dreams, Forest Nightmares: the paradox of old growth in the inland west. Washington: University of Washington Press. 1995.ROBBINS, William G. Landscapes of Conflict: the Oregon story, 1940-2000. Washington: University of Washington Press. 2004. ROBBINS, William G. Landscapes of Promise: the Oregon story, 1800-1940. Washington: University of Washington Press. 1997.STEEN, H.K. The U.S. Forest Service: a history. (?): Ed. Centennial (?). 2004.

13 “Corte-limpo". Tradução livre. Provavelmente o mesmo princípio da clareira (Nota dos tradutores). 
que como madeira nobre. Pior ainda, o pinheiro-torcido cresce tanto em uma clareira, que as outras plantas não têm a menor chance. Agentes florestais chamam isto de "dog-hair regeneration" "14, porque as árvores são tão próximas entre si quanto os pêlos de um cachorro. Um veterano me mostrou um grupo tão sobreposto que brincou, dizendo que deveríamos chamar o método de "frog-hair regeneration" 15 .

Que perigo de incêndio este denso crescimento aciona. Nos verões secos do alto Oregon, tudo teria se incinerado - talvez até reabrindo espaço para o ponderosa - se não fosse pela política de "fire exclusion"16 do Serviço Florestal estadounidense. A “fire exclusion" era uma política que tanto o Serviço Florestal quanto as indústrias madeireiras concordavam, já que incêndios destroem madeira cara. Por volta de 1960, as florestas nacionais foram pontilhadas com torres de incêndio e a menor brasa era imediatamente apagada. Então os pinheiros-torcidos cresceram e cresceram, seguindo as clareiras e se espalhando pela paisagem. O Serviço Florestal não sabia o que fazer com eles. Tudo foi tentado: todos os tratamentos de desbaste ${ }^{17}$, cortes seletivos, plantios, queimas prescritas. Mas a única técnica que garante o crescimento do pinheiro ponderosa é o plantio muda por muda. Então, os canteiros de mudas precisam ser limpos dos pinheiros-torcidos para mantê-los à distância. Mas isso requer trabalho, que por sua vez, requer dinheiro. Hoje, estas plantações são possíveis apenas nas Cáscades orientais, quando o Estado pode colocar prisioneiros para trabalhar nelas.

$\mathrm{Na}$ época das grandes guerras entre ambientalistas e madeireiros, que estremeceram o nordeste do Pacífico no final do século, as Cáscades orientais - antes um centro extrativista - estavam fora de alcance, na prática. As serrarias haviam fechado e as árvores restantes simplesmente não eram valiosas o suficiente para valer uma briga. O clima é seco. O solo oferece pouca matéria orgânica; ao invés disso, oferece pedra-pomes e areia, escombros de uma erupção vulcânica de sete mil anos atrás. Pinheiros-torcidos, doentios, sinuosos e amontoados enchem a terra, dificilmente capazes de suportar tratamentos silviculturais específicos, quanto mais gerar lucro. Entra em cena a economia de cogumelos silvestres. Seu florescimento foi em sequência a um desastre longínquo: o acidente nuclear de Chernobyl, em 1986, que espalhou uma nuvem radioativa sobre a maior parte dos cogumelos europeus. A Europa, então, contratou o Noroeste Pacífico dos Estados Unidos para obter porcini (Boletus edulis), cantarelas (Cantharellus cibarius) e morelas (Morchella sp.). O negócio do matsutake se iniciou logo em seguida. Por sorte, as secas e arruinadas florestas das Cáscades centrais e orientais acabaram sendo generosos jardins de matsutake. O superávit japonês ainda era alto em 1990; os preços eram extraordinários. Por um breve período, em 1994, um mau ano para o matsutake em todo o mundo, o preço do matsutake central-cascadiano nas mãos dos apanhadores era 600 dólares a libra ${ }^{18}$. Um grupo de pesquisadores florestais calculou que os cogumelos valiam ao menos o mesmo preço, senão mais, que madeira nobre (ALEXANDER et al., 2002, p. 129-141).

Pessoas em situação de vulnerabilidade migraram para as montanhas. Lenhadores em decadência, bombeiros com flexibilidade de horários, soldados desmobilizados e "tradicionalistas" rurais, radicalmente conservadores que rejeitam o secularismo liberal das cidades estadounidenses, foram as primeiras pessoas a coletar cogumelos. Alguns traçaram circuitos anuais, de Idaho à Califórnia, seguindo os cogumelos. Na coleta de cogumelos, aprenderam as lições com os nipo-estadounidenses, que colhiam para a subsistência de suas comunidades havia um século. Mas ambos grupos foram logo varridos para a coadjuvância por uma maré de refugiados laotianos e cambojanos, que rapidamente se tornaram as figuras centrais na colheita

\footnotetext{
14 “Regeneração pêlo de cão”. Tradução livre. (Nota dos tradutores).

15 “Regeneração pêlo de sapo”. Tradução livre. (Nota dos tradutores).

16 "Exclusão de fogo". Tradução livre. (Nota dos tradutores).

17 Do original, "thinning treatments". (Nota dos tradutores).

18 Uma libra equivale a 453,5 gramas. (Nota dos tradutores).
} 
do matsutake. Muitos haviam chegado aos Estados Unidos, vindos de campos de refugiados na Tailândia, em meados de 1980, uma época de redução neoliberal dos serviços públicos. Poucos dominavam o inglês; muitos não tinham experiência de trabalho em centros urbanos. Todos tinham terríveis experiências de guerra e fuga. Deixados à mercê do desmonte do welfare state, encontraram nas florestas do Oregon consolo - e um modo de ganhar a vida. Tornaram-se ávidos e hábeis caçadores de cogumelos.

Talvez exista algum paralelo entre a confiança que permitiu aos estadounidenses acreditar que deveriam policiar árvores em florestas industriais e que deveriam policiar pessoas no Laos e no Camboja. Certamente essas histórias convergiram nas florestas do Oregon, onde pessoas prejudicadas aprenderam a viver em florestas prejudicadas. O matsutake tem prosperado entre os emaranhados de pinheiros-torcidos que haviam sido espalhados pelo "clear-cutting" e sua maturidade frutificante foi preservada pelo programa de "fire exclusion", do Serviço Florestal. Assim também o foram os coletores laotianos e cambojanos que, pela estação do matsutake, formam animadas aldeolas nos acampamentos industriais do Serviço Florestal, em meio à mata, utilizando não apenas os pinheiros-torcidos, mas todas as ervas e cogumelos que o meio tem a oferecer

\section{PAISAGEM TRÊS: TRACEJANDO GELEIRAS}

Foi com alguma surpresa que ouvi dos gerentes e pesquisadores florestais, na Finlândia, que eles viam seu trabalho em uma continuidade simples dos últimos cem anos de pesquisa silvicultural. Suas contrapartes do Oregon estadounidense estavam obcecadas com os erros e acertos dos seus sonhos de meados do século XX e após 1970, imaginaram uma tentativa de equilíbrio entre a extratividade e proteção ambiental como um novo começo. Mesmo agora, explicaram, o seu gerenciamento florestal era contestável e só às vezes funcionava. Na Finlândia, ao invés disso, os engenheiros florestais não ficavam na defensiva a respeito da ciência florestal. Enquanto admitem receber críticas, não notam problemas em combinar a proteção do ecossistema e a produção de madeira. Sustentabilidade, argumentaram, é atingida com maior eficácia através de intervenções controladas $^{19}$ (HANNELIUS, KUUSELA, 1995).

Uma parte da diferença entre o Oregon e a Finlândia é que as questões de biodiversidade florestal são menos urgentes na Finlândia. Por sorte, o gelo simplificou a flora finlandesa. A flora foi completamente suprimida por causa de glaciações repetidas e, quando os mantos de gelo derreteram, a distribuição de espécies para o norte foi reduzida pela necessidade de atravessar bacias fluviais em sentido leste-oeste. Apenas dois tipos de coníferas completaram a migração para norte: pinheiros-da-escócia (Pinus sylvestris) e abetos noruegueses (Picea sp.). Na metade setentrional da Finlândia, elas se juntam a duas espécies de bétulas (Betula sp.), assim como poucas outras espécies que não formam florestas. As geleiras, então, simplificaram a composição de espécies florestais; a Finlândia setentrional possui uma das menores diversidades arbóreas do mundo. A natureza cria o que os humanos se esforçam tanto para manter em outras áreas: florestas de pinheiros de monocultura prontas para o corte.

O trabalho da pesquisa florestal, como aprendi, tem sido sustentar a paisagem simplificada, criada pelas geleiras. Ao invés de grandes queimadas, que costumam limpar largas faixas de floresta uma vez a cada cem anos, engenheiros florestais as substituíram pelo "clear-cut" na mesma rotatividade. Para acelerar o desbaste natural, a floresta é podada a cada quinze ou vinte anos. Para simular a destruição do solo, causada por um incêndio massivo, advoga-se a prática de aragem ou raspagem após os últimos cortes. Isto é fatal para qualquer fungo que possa habitar aí. Mas, sem perturbação, os solos finlandeses tendem a ficar encharcados. Florestas úmidas e sem gerenciamento tendem a dar espaço para os abetos, árvores de crescimento

19 Do original, "timber-oriented interventions". Tradução livre. (Nota dos tradutores). 
lento e menos atrativas economicamente. Além disso, os agentes florestais me disseram que alguns fungos comestíveis - como a popular morela-falsa (Gyromitra esculenta) - prosperam no solo revolvido pelas técnicas pós-“clear-cut”. Não é preciso, dizem, se preocupar com os fungos.

Para minha surpresa, então, as florestas finlandesas que vi pareciam limpas e ordenadas como parques. O desbastamento criou clareiras entre as árvores posicionadas e galhos mortos e raízes protuberantes estavam completamente ausentes do solo. Na Finlândia setentrional, renas possuem o direito de pastar em qualquer lugar e acabam comendo os liquens que, de outra forma, cobririam a floresta em profusão ofegante. A fantasia japonesa da floresta de matsutake "ideal" - iluminada, limpa e aberta, onde uma mulher poderia andar de salto-alto com um guarda-chuva aberto - emerge na Finlândia através do trabalho de pesquisa científica para produção da madeira. Perturbações não precisam parecer desorganizadas.

Além do mais, a idade da floresta é ideal para a produção de cogumelos matsutake. A maior parte das florestas finlandesas foi derrubada entre 1950 e 1960. Madeira era a exportação mais importante da Finlândia no período. A economia do país - que mais tarde se dedicaria a celulares e assimilados - foi feita sobre a madeira. Finalmente, duas consequências que a Segunda Guerra causou sobre o país aceleraram o corte das florestas finlandesas. Como aliada da Alemanha, a Finlândia estava entre os perdedores da guerra. O governo aceitou pagar as indenizações de guerra para a Rússia, e o dinheiro foi levantado com toras de madeira. Na mesma época, a Rússia tomou uma grande parte da Finlândia oriental. Centenas de camponeses da Carélia - região que hoje pertence aos russos - foram reassentadas sobre a Finlândia recém reduzida. As florestas foram limpas e transformadas em campo, e novas estradas foram implementadas, facilitando o transporte da madeira. As florestas que rebrotavam desses cortes ambiciosos hoje são o lar dos matsutake finlandeses.

O micélio do matsutake (a parte subterrânea do fungo) está lá. Residentes japoneses na Finlândia têm recolhido matsutake em silêncio, por décadas. Está tudo pronto para a coleta. Os finlandeses são orgulhosos da convenção do "direito de todas as pessoas", que permite acesso universal a florestas para o aproveitamento de produtos não-lenhosos. Frutas selvagens já foram o produto de acesso livre mais popular, mas a coleta de cogumelos têm crescido em popularidade por mais de um século. Mesmo se os finlandeses não têm motivação para a apanha, há outros ansiosos pela oportunidade. Companhias que trabalham com as frutas facilitam a entrada sazonal de coletores do empobrecido nordeste tailandês, quiçá parentes dos coletores laosianos do Oregon.

Coletores são recrutados, também, da Rússia e da Ucrânia; alguns catam boletos para exportar para a Itália. Os importadores japoneses estão prontos. Desde que cientistas suecos anunciaram a compatibilidade de DNA entre o matsutake nórdico com o nipônico, os importadores ficaram ansiosos para adicionar os exemplares nórdicos em suas reservas. Mas onde, então, está o matsutake?

Eis o que aconteceu. No início de 2007, um famoso cineasta finlandês anunciou suas intenções de exportar matsutake finlandês para o Japão. Seminários foram organizados em todo o país para familiarizar os residentes com o cogumelo, que até então não era identificado como alimento. Os seminários estavam cheios de coletores em potencial; todos queriam aprender sobre este novo cogumelo. E, por coincidência, o outono de 2007 foi uma temporada de sucesso para o matsutake finlandês. Um jovem afirma ter achado mil quilos de matsutake. As colônias eram grandes e bonitas; as pessoas estavam praticamente tropeçando em matsutake. Nem mesmo as renas conseguiram acompanhar a safra, e muitos cogumelos simplesmente apodreceram. A mídia estava encantada; dezenas de artigos jornalísticos foram publicados para proclamar o mais novo produto finlandês. 
Pelo outono de 2008, entretanto, tudo havia mudado. A companhia de exportação havia fechado. Outras empresas estavam prontas para assumir o seu lugar - mas não havia cogumelos. O ano 2008 foi péssimo para o matsutake finlandês, e 2009 não foi muito melhor. Parece que os verões frios e úmidos da Finlândia simplesmente não eram adequados para uma produção prodigiosa de matsutake. No norte da Finlândia, as árvores produzem sementes viáveis talvez apenas uma vez a cada dez anos, por razões similares. É preciso um ano incomum para que uma safra farta de matsutake emerja na Finlândia.

Piorando a situação, um impacto ambiental distante, além dos limites da exportação de cogumelos comestíveis, contaminou metade da paisagem florestal finlandesa. A nuvem radioativa do acidente de Chernobyl passou sobre a metade sul da Finlândia, deixando um rastro de resíduos. Os importadores japoneses exigiam que cada lote de matsutake finlandês fosse testado para radioatividade, e apenas cogumelos acima do Círculo Ártico passam consistentemente ${ }^{20}$. Cada teste custa 125 euros. Não é economicamente viável expedir lotes pequenos.

Os promotores de matsutake finlandês não se desesperaram. Existe uma coisa que a Finlândia pode exportar melhor do que muitos outros lugares: a ideia de uma floresta de matsutake perfeita. O novo objetivo é atrair turistas japoneses. Lustrosas brochuras editadas em japonês promovem a pureza e beleza das florestas finlandesas e revelam o matsutake dentre os frutos que qualquer um pode coletar. De acordo com meu colaborador Shiho Satsuka, a Finlândia preenche bem as fantasias japonesas de beleza e plenitude da natureza. Em um programa de televisão japonês, devotado a realizar os sonhos das crianças, um garoto que ansiava por matsutake foi levado à Finlândia, onde pôde correr pela floresta, colhendo $\operatorname{cogumelos}^{21}$. Mesmo sem exportar quantidades de cogumelos, as florestas da Finlândia oferecem um sonho de uma natureza limpa e ordenada. Turistas não precisam visitar os desgastados “clear-cuts”, de onde esses parques oníricos brotaram.

\section{PAISAGEM QUATRO: JARDINS DA NOSTALGIA}

No Japão, o apelo por florestas perturbadas como centros de jardins no satoyama, as florestas de aldeia utilizadas pelos fazendeiros camponeses ${ }^{22}$. Os pilares da floresta satoyama ideal eram os carvalhos decíduos intensamente podados principalmente os konara (Quercus serrata). Pinheiros vermelhos japoneses (Pinus densiflora) eram seus companheiros e matsutake crescia junto a eles. Como no sudoeste chinês, esta paisagem era mantida por perturbações constantes. Mudanças de cultivo e corte de árvores mantinham a floresta jovem e aberta. Os carvalhos eram derrubados para virar lenha e carvão. Folhas e agulhas dos pinheiros foram recolhidas para servirem de leito aos animais, deixando o piso da floresta nu, com poucos detritos ou húmus. Com a ajuda de seus parceiros matsutakes, pinheiros prosperaram nesses lugares abertos e iluminados.

Chamar essa floresta de 'satoyama' é uma ideia relativamente nova - sem dúvida, é um produto da morte das florestas tradicionais rurais. Depois da Segunda Guerra Mundial, fazendeiros japoneses substituíram a lenha por combustível fóssil e animais de tração por tratores. Os carvalhos deixaram de ser cortados; o solo da floresta deixou de ser limpo. Os jovens se mudaram para as cidades, deixando o interior rural para os idosos. Os camponeses deixaram de visitar suas florestas. Os carvalhos sempre-verdes começaram a invadir esses espaços, criando uma cobertura de penumbra, onde nem os carvalhos decíduos

20 Na época de minha pesquisa na Finlândia, o Japão possuía critérios mais elevados de teste para alimentos que continham césio radioativo do que os usados na Europa. Alimentos não poderiam exceder 300 becquerels (Bq) por quilo. Após o acidente de Fukushima, em março de 2011, o Japão aumentou seu padrão para 500 Bq por quilo. Talvez mais matsutake da Finlândia seja exportado para o Japão no futuro, especialmente agora que muitos dos cogumelos japoneses são mais radioativos.

21 “Sekai no Hate made Itte Q" (programa do dia 14/10/2007).

22 TAKEUCHI, Kazuhiko; BROWN, Robert; WASHITANI, Izumi; TSUNEKAWA, Atsushi; YOKOHARI, Makoto. (Eds.). Satoyama: The Traditional Rural Landscape of Japan. Tokyo: Springer-Verlag Tokyo. 2003. 
nem os pinheiros poderiam sobreviver. Os pinheiros, estressados pela sombra e pela competição, também estavam vulneráveis a uma doença enfraquecedora, disseminada por nematódeos exóticos. O matsutake desapareceu. As florestas rurais foram sufocadas pelas árvores latifoliadas de folhas persistentes e pelos bambus invasores. Ao contrário de locais amigáveis à presença humana, essas florestas pareciam densas e abandonadas.

O movimento popular que emergiu para advogar a restauração da floresta 'satoyama', na década de 1980, reconheceu que elas faziam parte da história do abandono das florestas. Migrantes urbanos se tornaram 'cidadãos' ativos, deixando seus passados camponeses para trás. O desenvolvimento, por sua vez, deslocou florestas rurais com o crescimento urbano e suburbano. Ainda assim, muitos destes cidadãos lembravam-se das paisagens de sua infância - ou, ao menos, das visitas às casas de seus avós - com prazer e nostalgia. Florestas satoyama foram parte das paisagens agrárias que também consistiam em campos de arroz, canais de irrigação, jardins de cozinha e plantações de coníferas. Para a primeira geração nascida na cidade, plantas e animais do satoyama ficaram associados com a inocência das visitas infantis ao campo, assim como com os padrões nacionais de beleza. As estações foram imaginadas através dessas paisagens agrárias: flores primaveris das florestas abertas e suas bordas traziam vida nova; carvalhos decíduos e aceres ofereciam cores de outono. Vagalumes, libélulas, sapos, coelhos e outras criaturas amáveis prosperavam nas beiras, entre os campos, as florestas e os pequenos canais de irrigação. Todos esses eram ameaçados pela negligência do ambiente rural. As novas florestas sempre-verdes não sustentavam nada das cores e da vida associadas ao amor pelas estações ou com o prazer da infância. Em resposta, então, um vigoroso movimento cidadão brotou para reconstruir as paisagens rurais. Bandos de voluntários foram para o interior rural, para refazer a beleza das florestas perturbadas e campos japoneses. Os grupos de cidadãos têm apresentado diferentes objetivos. Um deles foi restaurar as florestas de matsutake.

Quando visitei os projetos de restauração das florestas de matsutake, admito, minha primeira reação foi de choque. Para uma estadounidense educada para a proteção da natureza, o trabalho de reconstrução parece assustadoramente destrutivo. Não apenas esses novos engenheiros florestais cortam quase todas as árvores; mas também desenterram do solo todo o fértil húmus que é gerado pela nova associação de espécies. Eles retiram todas as raízes, assim como a camada superior do solo, e levam tudo isso embora, deixando apenas escarpas íngremes e nuas. Em uma floresta matsutake reconstituída, o engenheiro me mostrou onde ele havia designado pessoas para retirar as camadas superiores com pás, deixando rochas se desmoronando. O declive era tão íngreme que mal conseguíamos nos equilibrar. "Mas, e a erosão?" - perguntei. "Erosão é bom”, ele explicou. Tudo isso havia sido feito para privilegiar os pinheiros e o matsutake.

A restauração dos satoyamas, entretanto, é compreendida não como destruição, mas como cura. Todos com quem falei a respeito da restauração do satoyama reiteraram os benefícios do trabalho intenso e do exercício ao ar livre para a saúde humana que o restauro das *florestas comunais garantem. Esse trabalho de cura é particularmente significante por conta do dano causado no país pela modernização, pelo rápido crescimento e pelos seus colapsos inesperados. As mesmas forças que causaram o abandono das florestas rurais levam as pessoas ao excesso de trabalho, ao suicídio e à fobia de espaços públicos. A restauração do satoyama é um trabalho que busca restaurar tanto as pessoas quanto a natureza. A intervenção nas paisagens naturais e nos hábitos humanos é igualmente desejável nessa compreensão da jardinagem. A tradição, com suas sustentáveis formas de beleza, oferece um guia para o nível correto de perturbação em cada uma delas.

Alguns historiadores, contudo, acreditam que a 'mui-amada' paisagem satoyama, muitas vezes fetichizada como tradição, é um produto do século XIX (TAKEUCHI, 2008) ${ }^{23}$. No início do período Meiji, ao que parece, a parte central do Japão estava bastante deflorestada, com muitas colinas nuas e em processo de erosão. Teve início o reflorestamento com

23 Entrevista com a autora. 
pinheiros. Os pinheiros criaram as condições que permitiram aos carvalhos decíduos a ocupação de novos territórios; e as florestas satoyama decolaram. Nos primórdios do século XX, as florestas de pinheiros estavam na idade certa para a produção de matsutake. De fato, na primeira metade do século XX, havia uma abundância de matsutake no Japão, e eles não eram particularmente caros. Apenas em 1970 houve o decréscimo de pinheiros, florestas satoyama e matsutake. Com esta queda, o preço do matsutake - e a sua necessidade de importação - aumentou.

O alto valor do matsutake, hoje, torna mais fácil gostar da reconstituição florestal do satoyama. Tradição ou não, lá pode-se sentir o sonho da abundância. O mote dos Cruzados Matsutake de Kyoto é "Vamos reconstruir as florestas para que todos possamos comer sukiyaki". As encostas reorganizadas como parques são iluminadas, amplas e verdes de pinheiros. No inverno de 2008, seu primeiro matsutake nasceu.

\section{CADEIAS DE COMMODITIES E CADEIAS DE CONCEITOS}

Negociantes de matsutake se importam com histórias de perturbação apenas até onde elas interfiram na pureza dos cogumelos. Cogumelos finlandeses são testados para radioatividade. Os chineses o são para pesticidas. Uma vez que os cogumelos passem nesses testes, eles entram no mercado sem a bagagem de suas histórias ambientais. Tornam-se equivalentes, separáveis apenas por estratégias de preço, as quais, por sua vez, são mais aproximadas às reputações nacionais do que às histórias de perturbação particulares de cada floresta.

Esse é o terrível traço das cadeias globais de commodities, que as retira de suas histórias de produção natural e social e as torna permutáveis por dinheiro. Esta dependência da transação monetária para identificar a qualidade de uma commodity justifica a reputação de cadeias globais de commodities como irresponsáveis em relação tanto ao trabalho quanto ao meio ambiente. Ambos, trabalho e meio ambiente, são apagados durante o processo de transferência do produto ao mercado; ele é vendido meramente pelo que é visto pelos mercadores e consumidores como características intrínsecas, divorciadas da história que os criou ${ }^{24}$. Como resultado, as cadeias globais de commodities são amorais. Elas não relatam as questões de bem-estar humano e não-humano.

Acadêmicos e defensores têm trabalhado duro para considerar como retornar essas questões de bem-estar às deliberações sobre cadeias de commodities. Uma intervenção essencial foi a invenção de novas formas de contação de histórias: as estórias da produção das commodities. O fascínio dos cidadãos japoneses com a floresta satoyama pode contribuir para esse tipo de contação de histórias, ao menos para a cadeia do matsutake. As florestas satoyama são reconstituídas com muito esforço, envolvendo os voluntários na apreciação pelo trabalho da perturbação. Matsutake é um produto incidental de todo este trabalho; ele não pode ser gerado diretamente. Amantes de cogumelos devem esperar pacientemente pelos processos vitais do fungo na floresta perturbada. Este aguardar é o início da apreciação de uma ecologia multiespecífica e de histórias abertas de paisagens.

Os defensores japoneses do satoyama têm tentado exportar o conceito ao redor do mundo. Satoyama oferece uma visão distinta de "sustentabilidade", na qual as relações humanas/não-humanas não são definidas por uma tolerância não-interferente, mas, ao invés disso, pelo trabalho duro de manutenção de regimes de perturbação amenos. Em sua maioria, a divulgação internacional do satoyama sinaliza para o valor cultural da beleza de paisagens agrárias estáveis. Mas o conceito poderia

24 Produtos domésticos japoneses as vezes são vendidos com maior atenção as suas histórias de produção, o que os garante um valor maior do que produtos equivalentes feitos em outros lugares. Em contraste, produção estrangeira, incluindo matsutake, é rotulada apenas com o seu país de origem. Regiões subnacionais, que poderiam oferecer um pouco mais de informação sobre as condições de produção, são excluídas dos rótulos de produtos estrangeiros por lei. 
ganhar ainda mais tração se estivesse disposto a ser aplicado em regimes mais arriscados de perturbação. A diversidade global de florestas de matsutake oferece um exemplo. Florestas de matsutake, como demonstrei, não são todas parecidas com parques de ordem e beleza (onde o são, como na Finlândia e no Japão, pouquíssimos cogumelos são produzidos). Contar suas histórias não nos leva a uma harmonia integral com a natureza. Ao contrário, eles nos abrem histórias de perturbação social e natural. Ainda assim, essas histórias são boas para serem contadas: boas não apenas para nos levar para as, frequentemente, angustiantes condições de vida na Terra, mas também para oferecer dicas sobre como acomodações multiespecíficas podem ser arranjadas apesar dessas condições.

A contação de histórias sobre satoyama é infusa com amor. Um acadêmico do satoyama falou para mim, com sinceridade, sobre sua jornada pessoal: sobre como ele estudou economia porque queria ajudar as pessoas, mas ficou desiludido com sua disciplina; sobre como se preocupou com seus estudantes entediados e indiferentes; sobre como ele relembrava a felicidade de passar os verões com a sua avó no campo; e sobre como havia ganhando acesso via universidade às paisagens satoyama negligenciadas. Hoje ele envia alunos para plantar arroz, fazer carvão e abrir a floresta. Eu vi o prazer nas faces e vozes de seus alunos. E também vi conversarem decepcionados sobre como eles haviam levado a mensagem do satoyama para o Laos, onde ninguém fazia a menor ideia sobre o que eles estavam falando.

O trabalho para os acadêmicos das cadeias de commodities é segui-las até os locais de sua produção e reconhecer sua diversidade - mesmo ao serem arrastados para dentro das conexões do capitalismo global. O mesmo trabalho é enfrentado pelos acadêmicos do que se poderia chamar de cadeias globais de conceitos - isto é, a difusão global de ideias (STADE, sem data). Tais conceitos facilitam o diálogo internacional, mas também encontram histórias separadas em locais nacionais e regionais variados. Para advogar por satoyama - ou sustentabilidade - através dos continentes, é necessário se aproximar das histórias de alteração de particulares pessoas e paisagens, mesmo que essa comparação traga questões em comum. Nesta época de destruição em massa, apreciar as formas e vida que povoam essas paisagens perturbadas é particularmente importante. Precisamos conhecer as variedades de perturbações que caracterizam nossa época. Satoyama é um ponto de partida inspirador - particularmente se seu alcance global admite variados regimes de alteração, que se tornaram locais onde habitam humanos e não-humanos ao redor do mundo.

\section{CODA: MAIS RUÍNAS SE APROXIMAM}

Justamente quando a Iniciativa Japonesa Para o Satoyama Global foi plenamente lançada, as condições para pensar as paisagens rurais japonesas mudaram completamente. Em 11 de março de 2011, a Usina Nuclear 1, de Fukushima, no nordeste do Japão, liberou uma nuvem de radioatividade, contaminando paisagens por milhas. Correntes eólicas e oceânicas, e o movimento das coisas vivas espargiram a radioatividade para longe e em todo lugar. Na costa da Califórnia, algas marinhas radioativas foram encontradas após um mês; atum contaminado com césio de Fukushima havia sido encontrado em San Diego, em agosto (CONE, 2012; ZABARENKO, 2012). Até o fim do ano, radiocésio de Fukushima estava sendo relatado em florestas finlandesas - isto é, na direção oposta dos ventos prevalentes, que primeiramente carregaram a radiação pelo Oceano Pacífico (STUK, 2012). Enquanto isso, embora a meia-vida do césio-137 seja de 30 anos, pesquisadores descobriram que os níveis de radiocésio de Chernobyl possuem uma duração muito maior em paisagens vivas. Na zona ao redor de Chernobyl, a "meia-vida ecológica" do césio-137 - isto é, o tempo estimado para que metade do césio desapareça da área - é de 180-320 anos (MADRIGAL, 2009). 
Materiais radioativos são facilmente incorporáveis a seres vivos. Fungos são coletores particularmente eficientes de césio radioativo. Fungo micorrízico - ou o fungo que vive em relação mutualística com as árvores - passa radioatividade para florestas e animais que dele se alimentem. Sob a sombra de Fukushima, é difícil sentir algo além de desespero pela destruição do meio ambiente patrocinada pela espécie humana. Nesses tipos de paisagens arrasadas, fungos, com seus altos níveis de radiocésio, dificilmente são portais de esperança. Sem dúvida, fungos são uma forte lembrança do porquê expor a Terra à contaminação radioativa é uma ideia péssima para os humanos e toda a vida.

Precisamos ser capazes de diferenciar entre formas de perturbação que são inimigas para toda a vida e essas que oferecem oportunidades multiespecíficas. Um ponto de partida é reconhecendo que nem todas as paisagens moldadas pela mão humana são tão mortais quanto aquela espalhada pela usina de Fukushima. É nessas pequenas diferenças que podemos procurar por esperança. Paisagens arrasadas são tudo o que temos, e precisamos explorar seus pedaços que ainda promovem a vida. As ruínas agora são nossos jardins. 


\section{REFERÊNCIAS $^{25}$}

ALEXANDER, Susan; PILZ, David; WEBER, Nancy S.; BROWN, Ed; ROCKWELL, Victoria A.; Mushrooms, Trees and Money: value estimates of commercial mushrooms and timber in the Pacific Northwest. Environmental Management. Vol. 30. No.1. pp. 129-141. 2002. Disponível em: http://www.pilzwald.com/dev/wp-content/uploads/2016/ links/2002AlexanderEtalMushTreesMoney.pdf. 2002. Acessado em 11/04/2018.

COGSWELL, P. Jr. Deschutes Pine Logging. EM: VAUGN, T. (Ed.). High and Mighty: selected sketches about the Deschutes Country. Portland, Oregon: Oregon Historical Society. Pp. 235-259. 1981.

CONE, Marla. Fukushima's radioactivity found in California kelp; levels spiked, then disappeared. Environmental Health News. 30/3/2012.

HANNELIUS, S.; KUUSELA, K. Finland, The Country of Evergreen Forest. Forssa: Forssan Kirjapaino. 1995.

LANGSTON, N. Forest Dreams, Forest Nightmares: the paradox of old growth in the inland west. Washington: University of Washington Press. 1995.

LEFEVRE, Charles K. Host Associations of Tricholoma Magnivelare, the American Matsutake. (Dissertação). Department of Philosophy. University of Oregon State. 2003. Disponível em: http://ir.library.oregonstate.edu/xmlui/bitstream/ handle/1957/13115/LefevreCharlesK2003.pdf?sequence=1. 2003. Acessado em 11/04/2018.

MADRIGAL, Alexis. Chernobyl exclusion zone radioactive longer than expected. Wired. 15/12/2009. Adendo dos Tradutores: Disponível em: https://www.wired.com/2009/12/chernobyl-soil/. 2009. Acessado em 11/04/2018.

NORDSTROM, Carolyn. Global Outlaws. Crime, money and power in the contemporary world. University of Carolina Press. 2007.

OGAWA, Mankoto. Matsutake no Seibutsugaku. Tokyo: Tsukiji Shokan. 1978.

ROBBINS, William G. Landscapes of Conflict: the Oregon story, 1940-2000. Washington: University of Washington Press. 2004.

ROBBINS, William G. Landscapes of Promise: the Oregon story, 1800-1940. Washington: University of Washington Press. 1997.

STADE, Ronald. Global Concept Chains: cultural engineering, political contestation, and global scenarios. (Dissertação). Sem data.

STEEN, Harold.K. The U.S. Forest Service: a history. Seattle: Ed. Centennial. 2004.

STUK. Radioactivity in forests. Atualizado em 10/5/2012. Adendo dos Tradutores: Disponível em: http://www.stuk.fi/web/ en/topics/environmental-radiation/radioactivity-in-forests. 2012. Acessado em 11/04/2018.

YAMIN-PASTERNAK, Sveta. How The Devils Went Deaf: ethnomycology, cuisine, and perception of landscape in the russian north. (Doutorado). Department of Philosophy. University of Alaska Fairbanks. 2007. Disponível em: https:// www.uaf.edu/files/rap/Yamin-Pasternak\%20dissertation\%202007.pdf. 2007. Acessado em 11/04/2018.

ZABARENKO, Deborah. Fukushima radiation seen in tuna off California. Reuters. 28/5/2012. Disponível em: http://www. reuters.com/article/us-japan-nuclear-tuna-idUSBRE84R0MF20120528. 2012. Acessado em 11/04/2018. 